\title{
Adrenaline junkies and white-knucklers: A quantitative study of fear management in haunted house visitors
}

\author{
Clasen, Mathias ${ }^{1}$, Marc Andersen $^{2}, \&$ Uffe Schjoedt ${ }^{2,3}$ \\ ${ }^{1}$ Department of English, Aarhus University, Denmark \\ ${ }^{2}$ Interacting Minds Centre, Aarhus University, Denmark \\ ${ }^{3}$ Department of the Study of Religion, Aarhus University, Denmark
}

\section{Acknowledgments}

This study received ethics approval (\#233/2016) from the Research Ethics Committee of Central Region Denmark. The authors would like to thank the Centre for Biocultural History and the Interacting Minds Centre, both at Aarhus University, for generous funding; Dystopia Haunted House for making their haunt available to the research team; and the research assistants who provided invaluable help with data collection and coding: Theiss Bendixen, Charlotte B. Bentsen, Nanna R. Dahl, Satine B. R. von Gersdorff, Bonnie Iburg, Mathilde Kellberg, Jens Kjeldgaard-Christiansen, Sofie L. Madsen, Anne B. Møller, Daniel I. K. Pedersen, Kristine Schulz, Peter M. Self, Martin Stigaard, Rina Vijayasundaram, and Lars Williams.

\section{Author Note}

Correspondence should be sent to Mathias Clasen, Aarhus University, Department of English, Jens Chr. Skous Vej 4, building 1481, 436, 8000 Aarhus C, Denmark. E-mail address: mc@cc.au.dk, telephone: +4587162631 .

To be published in Poetics, https://doi.org/10.1016/j.poetic.2019.01.002. Authors' manuscript. This paper is not the copy of record and may not exactly replicate the final, authoritative version of the article. 


\title{
Adrenaline junkies and white-knucklers: A quantitative study of fear management in haunted house visitors
}

\begin{abstract}
We investigate approaches to horror entertainment from two common consumer stances: 'the thrillseeking stance' in which adrenaline junkies seek maximal fear arousal and 'the fear-avoidance stance' in which so-called white-knucklers seek minimal fear arousal. Visitors of a haunted house attraction $(\mathrm{n}=$ 280) were invited to focus on either maximizing or minimizing their fear. Open-ended participant interviews and questionnaire data were used to map how adrenaline junkies and white-knucklers regulate fear, and also how reported fear experience and consumer satisfaction compare across the two groups. A host of antecedent and response-focused strategies, including cognitive, behavioral, and social strategies, were used to up- and down-regulate fear arousal. Notably, the results reveal hitherto uncharted strategies employed by adrenaline junkies to support and maximize their fear experience. Although adrenaline junkies report stronger fear experiences than white-knucklers, consumer satisfaction remains relatively similar across the two groups, indicating that both stances can lead to satisfying consumer experiences. The study thus helps explain the paradoxical appeal of frightening entertainment by illuminating how consumers deliberately up- and down-regulate fear arousal in pursuit of the optimal experience.
\end{abstract}

\section{Keywords}

Haunted attractions, recreational fear, fear management, fear regulation, horror, immersion.

\section{INTRODUCTION}

Horror entertainment has been a mainstay of culture for hundreds of years and exists across media platforms, from film and literature to virtual reality and commercial haunted attractions. It is a persistently popular and profitable genre. Immersive, interactive horror experiences, such as those offered by digital horror video games and haunted attractions, have become increasingly popular in recent years (Clasen, 2017; Kerr, 2015; Ndalianis, 2012). Such consumer experiences intensify the negative affect produced through horror in traditional narrative media and thus put into stark relief the need to resolve the paradox of horror (Carroll, 1990): Why do people willingly seek out dysphoric experiences for recreational purposes? That question has attracted the attention of researchers from a range of fields (Andrade and Cohen, 2007; Bantinaki, 2012; Tudor, 1997). The present study suggests a crucial role for deliberate fearmanagement strategies in the consumer experience. 


\section{Adrenaline junkies vs. white-knucklers: Two stances toward recreational fear}

The widespread penchant for fear-inducing entertainment is highly peculiar and scientifically intriguing. Even though fear evolved to protect organisms from harm through motivating defensive behavior in response to relevant stimuli (Öhman and Mineka, 2001), many people seek out cultural activities that allow them to explore fear outside of its biological niche. Consider the audience for a horror movie. Some people are clearly enjoying the rush and thrill of fear, terror, and dread; others are clearly at their limit and just want to make it through the experience in one piece and without major psychological damage. Supposedly, all audience members get some pleasure from the experience, but people seem to approach the genre in different ways and for different reasons. We suggest that there are two overarching approaches or stances toward horror entertainment: A thrill-seeking stance and a fear-avoidance stance. These two stances correspond to Robinson et al.'s distinction between "adrenaline junkies" and "whiteknucklers" among horror film viewers (Robinson, Callahan and Evans, 2014). The adrenaline junkie wants to maximize emotional arousal, whereas the white-knuckler wants to keep emotional arousal at a minimal level.

Presumably, but beyond the scope of the study, these stances reflect individual differences in personality traits and motivational profiles. Indeed, previous research has found that Openness to Experience and sensation-seeking predict liking of horror media and frequency of use (Lang et al., 2017; Clasen, Kjeldgaard-Christiansen and Johnson, 2018). However, existing research says little about the distribution of consumers across the two stances. Robinson et al.'s findings suggest a fairly even distribution with slightly more adrenaline junkies than white-knucklers, but they work with a small sample ( $n=38)$. More importantly, research into the strategies that white-knucklers and, in particular, adrenaline junkies actively employ to manage fear levels is currently lacking.

\section{Strategies for managing fear}

Fear is an unpleasant emotion that most people seek to minimize in their everyday lives. Fear-inducing stimuli, however, are impossible to avoid entirely, so people use a range of coping strategies for managing fear (Folkman and Lazarus, 1988). A useful distinction for our purposes is that between antecedent and response-focused strategies (Gross, 1998; 2015). Antecedent strategies are aimed to keep unpleasant emotions from activating in the first place, whereas response-focused strategies are employed when the unpleasant emotion is already active. To take an example from the domain of horror entertainment, reminding oneself that the zombies are just actors and closing one's eyes to avoid jump scares are examples of antecedent strategies to keep fear down. To perceive the attacking zombies as scarily real, in a fear-struck way, and then try to 'man up' or 'calm down' would be examples of response-focused strategies to keep fear down. Generally, antecedent strategies seem to work better than 
response-focused ones because, once activated, fear responses mediated by the amygdala cascade throughout the body's autonomous nervous system and are difficult to control (Öhman and Mineka, 2001).

But what about people who intentionally seek out the fear experience, in particular those who seek maximal fear stimulation (the adrenaline junkies)? Do they also employ deliberate strategies to support and maximize their fear experience? Do adrenaline junkies use antecedent strategies to deliberately amplify their fear experience? And how may response-focused strategies work, if the aim is to sustain the thrill of fear? If adrenaline junkies actively use antecedent and response-focused strategies to up-regulate and to control their arousal, corresponding feelings of mastery may explain why this group finds fear-inducing stimuli to be both tolerable and enjoyable. Yet no studies, to our knowledge, have described how adrenaline junkies up-regulate emotional arousal to optimize their desired horror experience.

In particular, if adrenaline junkies truly aim to immerse themselves in fear, the ability to become immersed in situations more generally could be fundamental for their consumer experience. Immersion, or the sense of being "present" in a mediated world (Thompson et al., 2018), does appear to be crucial to the horror experience. Lynch and Martins (2015), in their empirical study of frightening video games, found that "presence" (via interactivity) increased fear in response to such games. If one is investedcognitively, emotionally, and imaginatively - in the mediated world, one is likely to experience the intended emotions more strongly and find the experience more enjoyable (Green, Brock and Kaufman, 2014). Conversely, trying to watch a horror film while finishing one's homework in arithmetic, say, is unlikely to produce strong emotional engagement. While the phenomenon of being immersed in a mediated world is probably universal, the cognitive mechanisms underlying the process are poorly understood (Thompson et al., 2018). Moreover, researchers use a variety of terms to describe conceptually similar phenomena: "transportation," "immersion," "absorption," "narrative engagement," and "the literary illusion" (Thompson et al., 2018, p. 211).

The potential relationship between the individual's ability to become absorbed in a situation (trait absorption) and horror experiences has not been investigated. Individuals differ in their tendency for seeking absorbing and self-altering experiences, and in the ease with which they achieve absorption (Tellegen and Atkinson, 1974). For some consumers the fear experience may come almost automatically, while others may struggle to become absorbed and use quite elaborate strategies to achieve immersion. Indeed, some evidence suggests that trait absorption may play an important role in immersion in mediated environments (Weibel, Wissmath and Mast, 2010).

The fear management strategies employed by people in response to media remain only partially understood, even as psychologists have found unpleasant film scenes useful as stimuli in the study of 
emotion regulation (Hofer and Allemand, 2017). Media psychological research suggests that young viewers of frightening media habitually use deliberate strategies for reducing fear levels (Cantor and Wilson, 1988; Hoffner, 1995). However, this research has focused on children and young adults (Wilson, Hoffner and Cantor, 1987; Cantor and Wilson, 1988; Hoffner, 1995; Harrison and Cantor, 1999; Cantor, 2002). There is very little research on the use of fear management strategies across individual traits, gender, and age, even though adults of both sexes are clearly major consumers of horror (Clasen, Kjeldgaard-Christiansen and Johnson, 2018). Previous research has found that males are slightly more likely to report enjoyment of horror (Clasen, Kjeldgaard-Christiansen and Johnson, 2018), and has suggested a curvilinear relationship between age and horror liking, with an increase in childhood, a peak in adolescence, and a slow decrease throughout adulthood (Hoffner and Levine, 2005). Yet many horror films are restricted to adult audiences, and many haunted attractions are open only to adults. Empirical research on adults' fear management in response to horror media is needed.

Most research on fear management in response to media, then, has focused on children and young adults and has used clips from frightening films as stimuli. The emerging consensus suggests two overarching types of coping strategies: cognitive and behavioral (Cantor and Wilson, 1988; Hoffner, 1995). Cognitive coping strategies involve self-directed mental regulation, such as distracting oneself from the fear-inducing media or reminding oneself about the fictional nature of the presentation, e.g. reassuring oneself that "it's just a movie." Behavioral strategies involve removing oneself physically from the frightening stimulus or covering one's eyes. Harrison and Cantor (1999) found that younger viewers (preschool children) tend to use behavioral strategies in response to frightening visual media. In contrast, older children are more likely to use cognitive strategies (see also Cantor and Wilson, 1988; Cantor, 2002).

Existing research on fear regulation in response to frightening media is fascinating but not without methodological and theoretical limitations. Apart from the lopsided focus on young consumers, an important point of criticism is the relatively poor context for intense immersion in the settings applied in previous research. Except for Lin's (2017) study on coping in response to horror in virtual reality, the research focuses on consumers responding to so-called flat-screen media. Although Lin's use of VR is innovative and the rapidly evolving technology offers unique opportunities for examining immersion, VR tends to be a solitary experience and fails to capture the inherently social nature of most other recreational fear settings, and thus, misses the opportunity to study social strategies in groups. People rarely watch horror movies by themselves, and the vast majority of haunted house visitors come in small groups.

A major issue in the study of deliberate strategies for managing fear in horror entertainment, which may explain the pronounced lack of research on the strategies employed by adrenaline junkies, is the fact that most previous research has been concerned with the deleterious psychological effects of 
frightening media presentations on children, and so has focused on coping strategies for reducing fear levels (Cantor, 2002). Another reason is that such strategies are very difficult to investigate. It is difficult to design a good context for a sufficiently immersive and controlled research environment in which adrenaline junkies can achieve a high degree of immersion. We suggest that haunted attractions offer a solution to this problem.

\section{Haunted house attractions as testing ground}

Haunted house attractions have roots in the American Halloween tradition but have recently appeared in other nations (Morton, 2012). Many of the fright-inducing elements in haunted attractions overlap with the elements employed by other horror media, but whereas horror film and horror literature have enjoyed substantial scholarly interest, there is very little research on haunted house attractions (Clasen, 2017; Dezecache, Grèzes and Dahl, 2017; Hoedt, 2009; Kerr, 2015; Kerr, Siegle and Jahala, 2018). Such attractions come in different shapes and cater to different audiences. Some promise family-friendly fun, others potentially traumatizing "extreme" experiences.

Haunted house attractions provide a unique setting for investigating the range of cognitive, behavioral, and social strategies employed by adrenaline junkies and white-knucklers to manage fear responses. They are live-action experiences where visitors buy entrance to a set, often a building, which is designed to induce feelings of fear, anxiety, disgust, and disquiet. Scare actors populate the set and use a variety of scare tactics, from make-up that suggests bodily damage or distortion to threatening behavior (see Fig. 1). By situating the visitor in an empirical environment replete with cues of danger, haunted attractions may be closer to horror video games and virtual reality than to observational media such as movies. Like horror video games, most haunted attractions use a combination of scripted narrative sequences and interactive elements, but with the difference that a visitor is physically present in the threatening world, while aggressive survival responses are prohibited (i.e., there is no way of fighting back without being evicted from the attraction).

In the present study, we use questionnaires and open-ended interviews to examine the strategies employed by adrenaline junkies and white-knucklers to manage their fear as they go through a haunted house attraction in Denmark.

[INSERT Fig. 1. AROUND HERE. CAPTION: Fig. 1. One of the scare actors encountered by guests in the haunted attraction. This muscular individual terrifies guests through a behavioral display of violent hostility and the dissonance-inducing mask. Photo: Andrés Baldursson, Baldursson Photography. Reproduced with permission.] 


\section{METHODS}

\section{Study context}

The study was conducted at the Dystopia Haunted House, a commercial haunted house attraction in Vejle, Denmark. Dystopia Haunted House, which is mainly run by volunteers, attracts approximately 6,000 visitors every Halloween, and is located in an old worn-down factory building. In terms of fright level, it is a mid-range attraction, promising genuinely frightening but not "extreme" entertainment. No customers under the age of 13 are allowed entry. Visitors are led through 30 different rooms which are designed to target different fears, such as the fear of confinement in small, dark rooms and the fear of infection in rooms with cues of disease, such as actors in zombie make-up (see Fig. 2). Visitors walk through in groups of typically four or five individuals, and a complete walk-through takes about 30-35 minutes. Visitors can at any time abort their visit by raising their arms over their head, in which situation they are escorted out by a guard (according to Dystopia Haunted House, about 5\% of visitors abort their visit).

[INSERT FIG. 2 AROUND HERE. CAPTION: Fig. 2. Scare actors in zombie make-up, exhibiting cues of hostility and contagion. Photo: Henriette Klausen. Reproduced with permission.]

\section{Participants}

280 visitors participated in the study (135 female, 144 males ( 1 participant did not indicate gender); mean age $=26.6$, ranging from 13 to 70 years). 149 participants ( 75 females, 74 males; age: mean $=26.6$, range =14-64) chose the 'thrill-seeking stance' condition, and 131 participants ( 60 females, 70 males, 1 missing; age: mean $=26.5$, range $=13-70$ ) chose the 'fear-avoidance stance' condition. Participants from both conditions were asked about horror preference and frequency of use and reported similar patterns. ${ }^{1}$

\section{Procedures}

Visitors were recruited for the study upon arrival at the Dystopia site. Assuming that free choice would reflect a preference for either the thrill-seeking stance or the fear-avoidance stance, we invited the participants to freely choose between focusing on maximizing or minimizing their fear in the haunt. In

\footnotetext{
${ }^{1}$ Participants were asked about the extent to which they agreed with the statement: "I like being scared by horror entertainment" on a 9-point likert scale ranging from -4 to 4 . On average, the participants in the maximize fear condition reported 1.8 points $(\mathrm{SD}=2.6)$ while the participants in the minimize fear condition reported 1.3 points $(\mathrm{SD}=2.8)$. They were also asked how often they had used horror entertainment within the last year. In the maximize fear group, 3.4\% reported "almost daily", $6.7 \%$ reported "several times a week", $6.0 \%$ reported "once a week", $17.4 \%$ reported "several times a month", $11.4 \%$ reported "once a month", $16.8 \%$ reported "several times a year", $13.4 \%$ reported "once a year" and $14.8 \%$ reported "never". $10.1 \%$ did not answer the question. In the minimize fear group, 3.1\% reported "almost daily", $8.4 \%$ reported "several times a week", $8.4 \%$ reported "once a week", $21.4 \%$ reported "several times a month", $8.4 \%$ reported "once a month", $16.0 \%$ reported "several times a year", $10.7 \%$ reported "once a year" and $21.4 \%$ reported "never". $2.3 \%$ did not answer the question.
} 
return we offered to reimburse their admission. Those who accepted signed a participant consent form and completed a short pre-questionnaire. Before entering the haunt, each group of participants (ranging from 3 to 6 individuals) was given further instructions by a research leader to ensure that participants would focus on their task. Adrenaline junkies - participants who had chosen to focus on maximizing their fearwere given the following verbal instructions (translated from Danish):

Thank you for participating in our study. Our research interest is how people handle fear. We are interested in how people avoid being scared, but we are also interested in what people do to become maximally scared. You have chosen to focus on becoming maximally scared. It is important that you take this task seriously during the entire walkthrough. We are recording your behavior and facial expressions with night vision cameras inside the haunt, which will be subject to analysis. When you exit the haunt, we will ask you what you did to get maximally scared. This is our research interest. You are allowed to think about how you will get scared before you enter the haunt. Any questions? Good luck!

The 'minimize fear' groups - the white-knucklers — were given the following instructions:

Thank you for participating in our study. Our research interest is how people handle fear. We are interested in how people avoid being scared, but we are also interested in how people manage to become maximally scared. You have chosen to not get scared. It is important that you take this task seriously during the entire walkthrough. We are recording your behavior and facial expressions with night vision cameras inside the haunt, which will be subject to analysis. When you exit the haunt, we will ask you what you did to not get scared. This is our research interest. You are allowed to think about how you will not get scared before you enter the haunt. Any questions? Good luck!

These verbal instructions were given approximately verbatim to every group of each challenge (maximize and minimize groups, respectively), but the research leader adapted the instruction if participants had questions or seemed to not understand the instruction, or judged participants to not take the challenge seriously, in which case he further emphasized the importance of taking the challenge seriously in return for the ticket reimbursement. As indicated in the instructions, we recorded video footage of participants inside the haunt (this was also accepted by participants in the consent form), but the low image quality of these video recordings did not allow further analysis. Emphasizing the video recording in the instruction acted to further ensure that participants would focus on their task.

Participants were then taken through the Dystopia haunt like regular guests, and after exiting the haunt, participants were immediately interviewed by research assistants. All participants were asked the same set of questions and given the chance to elaborate on their replies. Research assistants simply asked what the participants had done to reach the targeted states in the haunt. Vague answers were followed up 
by a prompt to supply concrete examples. The brief interviews were recorded for verbatim transcription. Finally, participants completed the post-haunt questionnaire before their tickets were reimbursed.

\section{Data and materials: questionnaires, scales, and interviews}

The pre-haunt questionnaire included basic demographic information (e.g. gender, age), a Danish translation of the Tellegen Absorption Scale (TAS, full scale with yes/no responses, Tellegen and Atkinson, 1974), and a ten-point expectancy measure of how scared participants expected to be inside the haunt (0-9). The post-haunt questionnaire included items relating to participants' experience in Dystopia, including ten-point scales asking how scared they had been (fear level) and the degree to which they liked the experience (consumer satisfaction). Open-ended interviews with participants asked about the strategies they used inside the haunt to maximize or minimize their fear. Some questionnaire items were included for exploratory purposes and were not included in the final data analysis (but see 'Data Availability' below).

\section{Content analysis of open-ended interviews}

The transcribed interviews were initially coded bottom-up by the research leaders, which produced a coding sheet that included an array of conceptual categories pertaining to cognitive, behavioral, and social strategies. The coding sheet generated by this inductive coding procedure was then used by an independent coder to code the transcribed interviews once more, adjusting the list in the process. Finally, a second independent coder used the finalized coding sheet to categorize the strategies observed in the interviews. The inter-coder reliability between the two independent coders was assessed using Cohen's kappa (Cohen, 1960) and the level of agreement was assessed using the Landis and Koch scale (Landis and Koch, 1977). To perform the analysis, we used 'irr,' version 0.84 (Gamer, Lemon and Singh, 2012) and the statistical software R (R Core team, 2012).

\section{Statistical analysis of questionnaire data}

To explore the effects of condition (thrill-seeking stance vs. fear-avoidance stance), gender, age, and absorption on self-reported fear experience, we performed an ordinal regression on the relationship between condition, gender, age, absorption, and fear scores, using the 'ordinal,' version 2015.6-28 (Christensen, 2015) and the statistical software R (R Core team, 2012). The same procedure was used to investigate the effects of condition (thrill-seeking vs. fear-avoidance), gender, age, and absorption scores on consumer satisfaction. 


\section{Data availability}

The data generated and analyzed during the current study are available through the Open Science Framework (link: https://osf.io/wpu7r/) ([Dataset] Clasen, Andersen and Schjoedt, 2019).

\section{RESULTS}

\section{Content analysis of interviews}

Inter-coder reliability: The two independent coders of the transcribed interviews agreed in $96.4 \%$ of the identified categories $(K=0.70)$, which corresponds to a substantial strength of agreement according to a widely used reference paper (Landis and Koch, 1977).

\section{Strategies employed by adrenaline junkies}

For an overview of the fear management strategies reported by adrenaline junkies, see Table 1. Adrenaline junkies mainly employ cognitive strategies. 55\% report that they sustained immersion by maintaining focus on the fear-inducing stimuli (in contrast to white-knucklers' efforts to divert attention away from scary events). 19.5\% say they focused on a dangerous framing (telling themselves that the stimuli are real and/or dangerous) to achieve the desired state. $14.1 \%$ attempted to engage in the scary narrative provided by the Dystopia actors, e.g. by paying close attention to the unfolding story. $8.1 \%$ of adrenaline junkies allowed themselves to scream, and $4 \%$ attempted to keep their eyes open to visually attend to the scariest parts. $6 \%$ of adrenaline junkies allowed themselves to actively seek bodily contact with other group members, presumably to feel the fears of others, while $4 \%$ reported staying close to the other group members in order to experience fear vicariously (for examples, se Table 1.).

A significant number of adrenaline junkies report achieving their desired state 'automatically.' $21.5 \%$ explained that it 'just happened.' While this may speak to the quality of the Dystopia setting, which is explicitly designed to evoke fearful responses in paying customers, it may also indicate that some people have the ability to become immersed more easily than others (trait absorption). This potential link was the reason why we included the Tellegen Absorption Scale in the study. However, comparing the average TAS scores of those $21.5 \%(\mathrm{M}=17.25, \mathrm{SD}=5.79)$ with the average of those who reported using explicit strategies for immersion $(\mathrm{M}=16.53, \mathrm{SD}=4.66)$, we found no significant differences. 


\section{TOP TEN STRATEGIES EMPLOYED BY ADRENALINE JUNKIES}

\begin{tabular}{|c|c|c|c|}
\hline Strategy (Code)* & Type & $\begin{array}{l}\text { Frequency in } \\
\text { reports }(\%)\end{array}$ & Examples \\
\hline Cognitive (C2) & Focus on situation & $55.0 \%$ & "I tried to 'be in it'." \\
\hline Cognitive (C3) & Dangerous framing & $19.5 \%$ & $\begin{array}{l}\text { "I tried to remind myself that it was } \\
\text { real." }\end{array}$ \\
\hline Cognitive (C6) & Engage in narrative & $14.1 \%$ & $\begin{array}{l}\text { "I tried to follow what [the actors] said } \\
\text { and get into my role." }\end{array}$ \\
\hline Behavioral (B5) & $\begin{array}{l}\text { Produce fearful } \\
\text { vocalization }\end{array}$ & $8.1 \%$ & $\begin{array}{l}\text { "I let myself scream as much as } \\
\text { possible." }\end{array}$ \\
\hline Cognitive (C5) & $\begin{array}{l}\text { Boost emotional } \\
\text { responsiveness }\end{array}$ & $6.0 \%$ & $\begin{array}{l}\text { "I tried to become afraid ... I whipped } \\
\text { myself up." }\end{array}$ \\
\hline Social (S2) & $\begin{array}{l}\text { Seeking bodily } \\
\text { contact with others }\end{array}$ & $6.0 \%$ & "We held each others' hands a lot." \\
\hline Cognitive (C1) & Active immersion & $5.4 \%$ & "I just immersed myself." \\
\hline Cognitive (C9) & $\begin{array}{l}\text { Take events } \\
\text { seriously }\end{array}$ & $4.0 \%$ & $\begin{array}{l}\text { "I tried not to use humor ... to distance } \\
\text { myself from what was happening." }\end{array}$ \\
\hline Behavioral (B1) & $\begin{array}{l}\text { Keep visual } \\
\text { attention }\end{array}$ & $4.0 \%$ & $\begin{array}{l}\text { "I would normally close my eyes. But } \\
\text { I didn't. I forced myself to keep my } \\
\text { eyes open all the time." }\end{array}$ \\
\hline Social (S5) & $\begin{array}{l}\text { Talk of dangerous } \\
\text { framing }\end{array}$ & $4.0 \%$ & "We psyched each other." \\
\hline No explicit strategies & & $21.5 \%$ & $\begin{array}{l}\text { "[I did] nothing. It just happens } \\
\text { automatically." }\end{array}$ \\
\hline
\end{tabular}

Table 1: Strategies employed by embracers. See online supplementary material for complete list of coded categories of strategies and their frequencies.

\section{Strategies employed by white-knucklers}

For an overview of strategies reported by white-knucklers, see Table 2. $48.1 \%$ of the white-knucklers report using the time-honored strategy of reminding oneself of the fictional, non-dangerous nature of the stimulus (non-dangerous framing). 23.7\% tried to keep 'cool' and suppress arousal. 19.1\% took a humorous approach to the scary events. $11.5 \%$ report breaking visual attention by closing one's eyes or 
looking down. White-knucklers generally reported more behavioral strategies for managing fear levels through obstruction of the senses than did adrenaline junkies. Social strategies were also more common among white-knucklers. $12.2 \%$ actively pursued bodily contact with other group members, e.g. holding hands, while $9.9 \%$ simply attempted to stay close to the other group members. 6,9\% thought about something else to avoid immersion, and 6.9\% focused on completing the haunt. Another 6.9\% attempted to suppress tendencies to express fear behaviorally. It is worth noting that $9.2 \%$ report achieving the desired no-fear state effortlessly.

\section{TOP TEN STRATEGIES EMPLOYED BY WHITE-KNUCKLERS}

\begin{tabular}{|c|c|c|c|}
\hline Strategy (Code)* & Type & $\begin{array}{l}\text { Frequency in } \\
\text { reports }(\%)\end{array}$ & Examples \\
\hline Cognitive (C3) & Non-dangerous framing & $48.1 \%$ & "I tried to imagine that it wasn't real." \\
\hline Cognitive (C5) & Emotional suppression & $23.7 \%$ & $\begin{array}{l}\text { "I tried to put a damper on [my } \\
\text { emotions]." }\end{array}$ \\
\hline Cognitive (C9) & Humorous approach & $19.1 \%$ & $\begin{array}{l}\text { "I made fun of it ... tried to see the } \\
\text { funniness of it." }\end{array}$ \\
\hline Social (S2) & $\begin{array}{l}\text { Bodily contact with } \\
\text { others }\end{array}$ & $12.2 \%$ & $\begin{array}{l}\text { "[I] held my friend's hand because then } \\
\text { you sort of felt safe." }\end{array}$ \\
\hline Behavioral (B1) & $\begin{array}{l}\text { Break visual attention } \\
\text { (look down/away/close } \\
\text { eyes) }\end{array}$ & $11.5 \%$ & $\begin{array}{l}\text { "I looked down. Didn't look at any of the } \\
\text { actors. At all." }\end{array}$ \\
\hline Social (S1) & Stay close to others & $9.9 \%$ & $\begin{array}{l}\text { "I kept the others close to me at all } \\
\text { times." }\end{array}$ \\
\hline Cognitive (C1) & $\begin{array}{l}\text { Active counter- } \\
\text { immersion }\end{array}$ & $7.6 \%$ & "I tried not to get immersed." \\
\hline Cognitive (C2) & $\begin{array}{l}\text { Think about something } \\
\text { else }\end{array}$ & $6.9 \%$ & $\begin{array}{l}\text { "Thought about vacation, and what we've } \\
\text { been doing today." }\end{array}$ \\
\hline Cognitive (C4) & Focus on completion & $6.9 \%$ & $\begin{array}{l}\text { "I kept thinking that I just had to get } \\
\text { through this." }\end{array}$ \\
\hline Behavioral (B7) & Suppress fear behavior & $6.9 \%$ & $\begin{array}{l}\text { "I just sort of walked and kept my hands } \\
\text { in my pockets." }\end{array}$ \\
\hline $\begin{array}{l}\text { No explicit } \\
\text { strategies }\end{array}$ & & $9.2 \%$ & $\begin{array}{l}\text { "I didn't do anything ... it's not real so } \\
\text { I don't get affected." }\end{array}$ \\
\hline
\end{tabular}


Table 2: Strategies employed by white-knucklers. *See electronic supplementary material for complete list of coded categories of strategies and their frequencies.

Regression analyses of questionnaire data: fear experience and consumer satisfaction

Fear experience: the questionnaire data reveal significantly higher fear-scores in the adrenaline junkies (Mean $=7.63, \mathrm{SD}=1.66)$ compared to the white-knucklers (Mean $=4.28, \mathrm{SD}=2.82)(\mathrm{BETA}=2.5899$, $\mathrm{SE}=0.2643, \mathrm{p}<0.00001)$. Results also reveal a significant effect of gender on reported fear scores, indicating that female participants (Mean $=6.80, \mathrm{SD}=2.56$ ) on average had a 1.43 points higher fear score compared to male participants $($ Mean $=5.37, \mathrm{SD}=2.91)(\mathrm{BETA}=1.1487, \mathrm{SE}=0.2351, \mathrm{p}<$ 0.00001). We also observe a significant effect of age on reported fear: older participants reported less fear $(\mathrm{BETA}=-0.0539, \mathrm{SE}=0.0107, \mathrm{p}<0.00001)$. No significant effect of trait absorption scores was observed on reported fear $(\mathrm{BETA}=0.0256, \mathrm{SE}=0.0193, \mathrm{p}=0.18606)$.

Consumer satisfaction: Results reveal a small but significant effect of the 'fear condition' on consumer satisfaction, with a 0.67 points higher satisfaction score in the adrenaline junkies (Mean $=7.30$, $\mathrm{SD}=1.43)$ compared to the white-knucklers $($ Mean $=6.63, \mathrm{SD}=2.02)(\mathrm{BETA}=0.7528, \mathrm{SE}=0.2525, \mathrm{p}$ $=0.00286$ ). No significant effect of trait absorption scores was observed on consumer satisfaction (BETA $=0.0302, \mathrm{SE}=0.0213, \mathrm{p}=0.15703)$. Similarly, results revealed no significant effect of gender on consumer satisfaction $(\mathrm{BETA}=0.0016, \mathrm{SE}=0.2567, \mathrm{p}=0.99513633)$. Results did reveal a trend toward less consumer satisfaction in older participants $(\mathrm{BETA}=-0.0224, \mathrm{SE}=0.0119, \mathrm{p}=0.05935)$. 

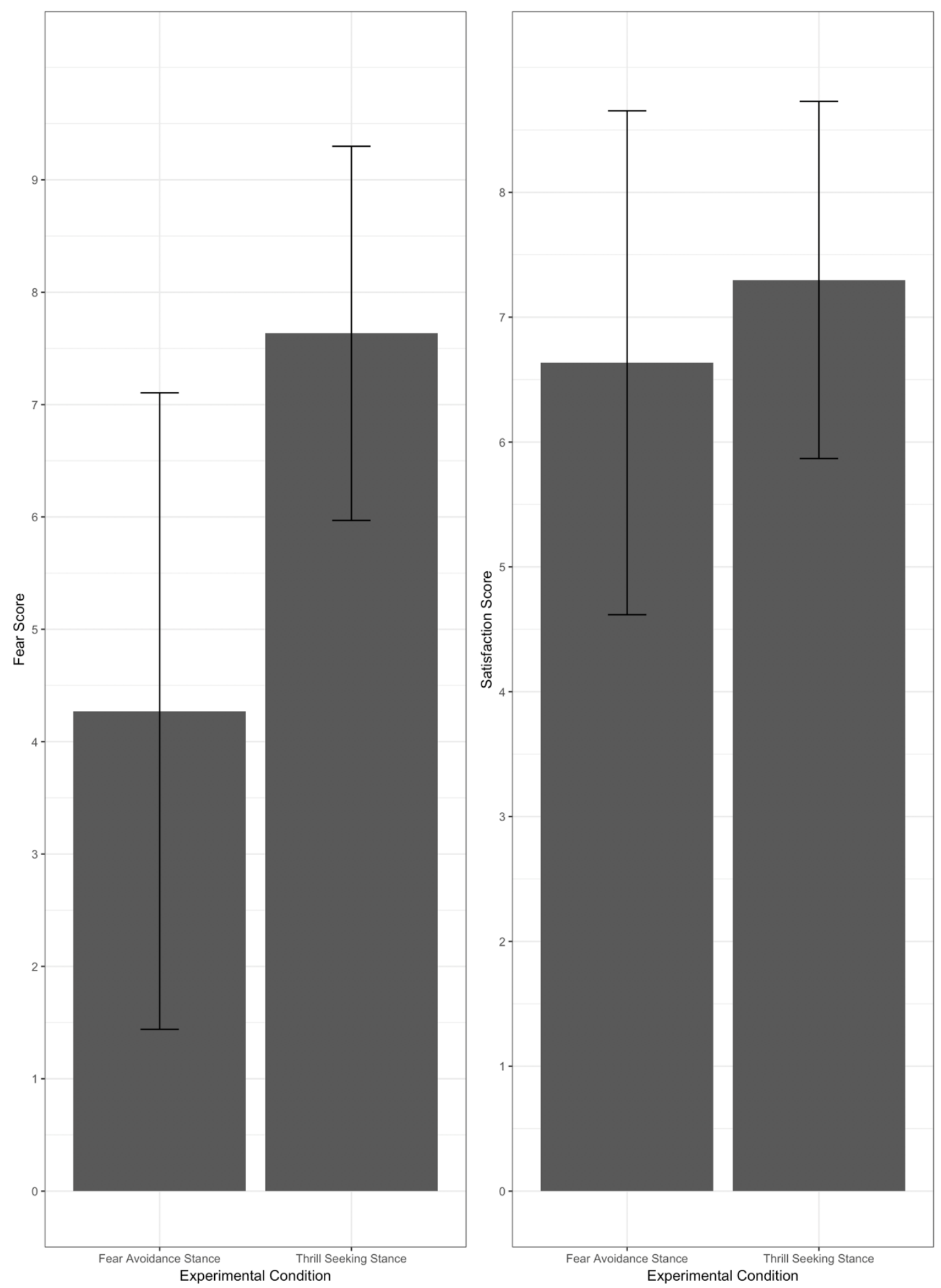

Figure 3: Participant fear score and satisfaction score as a function of experimental. Error bars represent SD. Please note the different y-axes. 


\section{DISCUSSION}

In this study, we investigated approaches to horror entertainment from two common consumer stances: the thrill-seeking stance, in which individuals seek maximum fear arousal, and the fear-avoidance stance, in which individuals seek to keep fear at a minimal level. The participants were allowed to freely choose to either maximize fear arousal (adrenaline junkies) or minimize fear arousal (white-knucklers), which produced two quite equal groups in terms of size and gender composition. Contrary to a stereotypical assumption that men tend to go for the thrill-seeking stance and women for the fear-avoidance stance, we find an equal distribution of the genders in the two conditions.

We find that both adrenaline junkies and white-knucklers employ a variety of cognitive, behavioral, and social strategies to achieve their desired states, which include both antecedent strategies and response-focused strategies. As expected, most of the strategies reported are antecedent strategies.

White-knucklers in the fear-avoidance stance mainly report regulating their fear through the use of cognitive strategies such as non-dangerous framing or by adopting a humorous perspective on the situation. Behaviorally, they also use antecedent strategies to avoid fearful stimuli by closing their eyes and by looking down (see Fig. 4). However, the white-knucklers also use response-focused strategies, e.g. by attempting to keep calm and by suppressing fear responses. Socially, white-knucklers attempt to inhibit fear by staying close to other group members and by keeping physical contact, e.g. holding hands.

[INSERT FIG. 4 AROUND HERE. CAPTION: Fig. 4. Haunt visitors respond strongly to confrontation with scare actor. The visitor closest to the actor employs a behavioral (B1) coping strategy to manage fear. Photo: Andrés Baldursson, Baldursson Photography. Reproduced with permission.]

The thrill-seeking stance has been much less studied. Like the white-knucklers, adrenaline junkies report using both antecedent and response-focused strategies. Cognitively, they mainly seek immersion by actively focusing on scary events, by placing the events in a dangerous framing, and by engaging with the narrative provided by the actors. Behaviorally, adrenaline junkies allow themselves to respond to the scary events, e.g. by screaming, and to force the uptake of fearful stimuli, e.g. by keeping their eyes open despite impulses to the contrary. Socially, they stay close to other group members, presumably, to enjoy fear vicariously, and they collaborate through verbal negotiation to make the entire setting and framing of the haunt feel more dangerous.

Although the adrenaline junkies seem to use fewer deliberate strategies than the white-knucklers, the observation that this group uses cognitive, behavioral and social strategies to achieve maximum fear 
underscores the important point that humans seem capable of both up- and down-regulating emotional arousal through conscious control.

The finding that adrenaline junkies use both antecedent strategies and response-focused strategies to support and amplify emotional arousal may help solve the paradox of horror - the peculiar fact that many people seek out fear-inducing entertainment. Even though the adrenaline junkies seek out fearinducing stimuli, they do so with a high degree of control. By actively imagining fearful scenarios and outcomes, for example, they deliberately prepare themselves for fearful stimuli which in turn become expected and predictable (or predictably unpredictable). They are ready to scream when the zombie comes roaring at them. For the adrenaline junkies, even response-focused strategies such as forcing oneself to keep one's eyes open, despite impulses to the contrary, will support a sense of mastery of the situation because they maintain control of the situation. Conceivably, this feeling of mastery and control is what makes the fearful experience tolerable and even enjoyable for the adrenaline junkie. It may be the ingredient that converts fear into thrill.

The efficacy of the adrenaline junkies' efforts in the haunt may be reflected by the observation that adopting the thrill-seeking stance is the strongest predictor of fear intensity in the haunt (see Figure 3). Of course, it is impossible to determine if this effect is driven by these efforts or if it derives from the contrast to the white-knucklers' efforts, or if it is caused by a third variable which has not been taken into account in our analyses. It would require a controlled experiment to determine this.

Beyond the effect of the two stances, we find effects of gender and age. Females report higher levels of fear, and fear decreases with age. Indeed, even though the sexes seem to be evenly distributed among horror consumers (Clasen, Kjeldgaard-Christiansen and Johnson, 2018), females tend to experience higher levels of fear than males (Campbell, 2013), and males tend to be socialized to avoid public displays of fear (Zillmann and Weaver, 1996). Males, then, seem to have less fear to suppress and more experience with fear suppression. Regarding age, evidence suggests that young horror viewers have difficulties coping with frightening media presentations (Cantor and Oliver, 1996) and that people improve coping skills with experience (Lynch and Martins, 2015) and age (Hofer and Allemand, 2017).

Contrary to our expectations, individual trait absorption scores did not predict fear in the haunt for either of the groups. The general ability to become immersed in situations does not seem relevant for the extent to which adrenaline junkies or white-knucklers experience fear. It is possible that the TAS scale is somehow unsuitable for this particular research question, or, as some researchers have suggested, that it is an unsuitable measure altogether (Council et al., 1986).

Interestingly, despite a statistically significant difference, we find that consumer satisfaction scores are similar for adrenaline junkies and white-knucklers, which indicates that adopting the thrillseeking stance and the fear-avoidance stance can both lead to satisfying consumer experiences. Perhaps 
the stances reflect two modes of experience that everyone can adopt if properly motivated. People who are genuinely scared of entering the haunt - such as visitors who, under social pressure, visit on a daremay be likely to automatically adopt the fear-avoidance stance, while consumers who either struggle with taking such attractions seriously or enjoy the rush of fear may seek enjoyment through the thrill-seeking stance. Presumably, both stances allow people to gain experience with fear in a safe context and to develop skills in fear management.

Intriguingly, for white-knucklers who genuinely fear the haunt, undergoing the frightening scenarios may be more akin to participating in dysphoric rituals than to passively observe other horror media. Extreme rituals often demand considerable emotion suppression from participants undergoing truly frightening scenarios (Schjoedt et al., 2013). Participation in such rituals has important social consequences for the members of the group, e.g. in terms of social status and social cohesion (Durkheim, 1912; Xygalatas et al., 2013a). Truly frightened visitors who boldly enter haunted attractions in small groups may demonstrate similar social effects after completion. Such effects could help explain why white-knucklers choose to visit haunted attractions despite their aversion toward fear.

Our study paves the way for future investigations into the psychological underpinnings of recreational fear. Future research might, for example, investigate relationships between preferred stance toward frightening media and personality characteristics, such as trait motivational reactivity (Lang et al., 2017). Moreover, the present analyses rely on questionnaire data and qualitative interviews. Such selfreport data may be confounded by the social psychological mechanisms of social desirability, demand characteristics, conformity bias, and poor personal judgement. Moreover, we partly rely on participants' recollection of events inside the haunted attraction. Such recollections may be faulty, especially given the high-intensity nature of the Dystopia Haunted House. Evidence from other high-arousal events, like participation in dysphoric collective rituals, suggests that participants may encode very few details during such events (Xygalatas et al., 2013b). Future studies should include behavioral and physiological measures to obtain more accurate and robust measures of fear management inside haunted attractions. Lastly, our study was not designed to demonstrate a causal relationship between stance and fear experience because the participants self-selected to either maximize or minimize fear. We have mapped the strategies employed in the two stances but future studies will have to use randomized allocation to determine if thrill-seeking and fear-avoidance strategies work effectively independent of individual preferences, e.g. if people who prefer one stance can successfully adopt the opposite stance.

\section{Conclusion}

The haunted house industry is rapidly expanding, raising questions about the appeals, functions, and psychological mechanisms of recreational fear. Our data show that consumers employ a range of 
cognitive, behavioral, and social strategies for managing fear. White-knucklers obstruct sensory immersion and inhibit natural fear responses in order to keep fear at a minimal level, while adrenaline junkies attempt to become frightened through role-playing and by actively seeking exposure to scary stimuli. Notably, our study reveals hitherto unknown strategies employed by adrenaline junkies to support and maximize emotional arousal. We believe these strategies may be crucial for understanding the paradox of horror. By actively supporting fear arousal, the adrenaline junkie makes the fear experience predictable and puts it under control. This feeling of mastery may be instrumental in turning otherwise frightening scenarios into enjoyable thrills. For the white-knucklers, who report similar satisfaction levels, the pleasure may reside primarily in the feeling of overcoming a challenge in fear-suppression.

\section{REFERENCES}

Andrade, E. B., \& Cohen, J. B. (2007). On the consumption of negative feelings. Journal of Consumer Research, Vol. 34 (3), 283-300. doi:10.1353/dss.2007.0102.

Bantinaki, K. (2012). The paradox of horror: Fear as a positive emotion. The Journal of Aesthetics and Art Criticism, Vol. 70 (4), 383-392. doi: 10.1111/j.1540-6245.2012.01530.x.

Campbell, A. (2013). The evolutionary psychology of women's aggression. Philosophical Transactions of the Royal society of London B: Biological Sciences, Vol. 368 (1631), 20130078. doi:

10.1098/rstb.2013.0078

Cantor, J. (2002). Fright reactions to mass media. In J. Bryant \& M. B. Oliver (Eds.), Media effects: advances in theory and research, (pp. 287-306). New York: Routledge.

Cantor, J., \& Oliver, M. B. (1996). Developmental differences in responses to horror. In J. B. Weaver \& R. Tamborini (Eds.), Horror films: research on audience preference and reactions, (pp. 63-80). Mahwah, NJ: Lawrence Erlbaum.

Cantor, J., \& Wilson, B. (1988). Helping children cope with frightening media presentations. Current Psychology Research and Reviews, Vol. 7, 58-75. doi: 10.1007/BF02686664

Carroll, N. (1990). The philosophy of horror, or, paradoxes of the heart. New York: Routledge.

Christensen, R. H. B. (2015). Ordinal - regression models for ordinal data. R package version 2015.6-28. http://www.cran.r-project.org/package=ordinal/.

Clasen, M. (2017). Why horror seduces. New York: Oxford University Press.

[Dataset] Clasen, M., Andersen, M., \& Schjoedt, U. (2019). Haunted House Dataset '16, Open Science Framework (https://osf.io/wpu7r/). doi: 10.17605/OSF.IO/WPU7R

Clasen, M., Kjeldgaard-Christiansen, J., \& Johnson, J. (2018). Horror, personality, and threat simulation: A survey on the psychology of scary media. Evolutionary Behavioral Sciences. Advance online publication. http://dx.doi.org/10.1037/ebs0000152 
Cohen, J. (1960). A coefficient of agreement for nominal scales. Educational and Psychological Measurement, Vol. 20 (1), 37-46. doi: 10.1177/001316446002000104

Council, J. R., Kirsch, I., \& Haefner, L. P. (1986). Expectancy versus absorption in the prediction of hypnotic responding. Journal of Personality and Social Psychology, Vol. 50 (1), 182-189. doi:

10.1037/0022-3514.50.1.182

Dezecache, D., Grèzes, J., \& Dahl, C. D. (2017). The nature and distribution of affiliative behavior during exposure to mild threat. Royal Society Open Science, Vol. 4 (8), 170265.

https://dx.doi.org/10.1098\%2Frsos.170265.

Durkheim, É. (1912). Les formes élémentaires de la vie religieuse [The elementary forms of religious life]. Paris, France: Alcan.

Folkman, S., \& Lazarus, R. S. (1988). Coping as a mediator of emotion. Journal of Personality and Social Psychology, Vol. 54 (3), 466-475. doi: 10.1037/0022-3514.54.3.466.

Gamer, M., Lemon, J. \& Singh I. F. P. (2012). irr: various coefficients of interrater reliability and agreement. R package version 0.84. https://CRAN.R-project.org/package=irr

Green, M. C., Brock, T. C., \& Kaufman, G. F. (2014). Understanding media enjoyment: The role of transportation into narrative worlds. Communication Theory, Vol. 14 (4), 311-327. doi: 10.1111/j.14682885.2004.tb00317.x.

Gross, J. J. (1998). The emerging field of emotion regulation: An integrative review. Review of General Psychology, Vol. 2 (3), 271-299. doi: 10.1037/1089-2680.2.3.271

Gross, J. J. (2015). Emotion regulation: Current status and future prospects. Psychological Inquiry, Vol. 26 (1), 1-26. doi: 10.1080/1047840x.2014.940781

Harrison, K., \& Cantor, J. (1999). Tales from the screen: enduring fright reactions to scary media. Media Psychology, Vol. 1 (2), 97-116. doi: 10.1207/ s1532785xmep0102_1

Hoedt, M. (2009). Keeping a distance: the joy of haunted attractions. Irish Journal of Gothic and Horror Studies (7). Retrieved December 20, 2017, from https://irishgothichorror.wordpress.com/issue7/.

Hofer, M., \& Allemand, M. (2017). Dispositional and situational emotion regulation in younger and older adults. The Journal of Gerontopsychology and Geriatric Psychiatry, Vol. 30 (3), 109-118. doi: 10.1024/1662-9647/a000171.

Hoffner, C. (1995). Adolescents' coping with frightening mass media. Communication Research, Vol. 22 (3), 325 - 346. doi: 10.1177/009365095022003003

Hoffner, C. A., \& Levine, K. J. (2005). Enjoyment of mediated fright and violence: A meta-analysis.

Media Psychology, Vol. 7 (2), 207-237. doi:10.1207/S1532785XMEP0702_5.

Kerr, M. (2015.) Scream: chilling adventures in the science of fear. New York: PublicAffairs. 
Kerr, M., Siegle, G., \& Jahala, O. (11 Oct. 2018). Voluntary arousing negative experiences (VANE): Why we like to be scared. Emotion. No pagination specified. doi: 10.1037/emo0000470.

Landis, J. R., \& Koch, G. G. (1977). The measurement of observer agreement for categorical data. Biometrics, Vol. 33 (1), 159-174. doi: 10.2307/2529310

Lang, A., Bradley, S. D., Sparks Jr., J. V., \& Lee, S. (2017). The Motivation Activation Measure (MAM): How well does MAM predict individual differences in physiological indicators of appetitive and aversive activation? Communication Methods and Measures, Vol. 1 (2), 113-136. doi: $10.1080 / 19312450701399370$.

Lin, J. (2017). Fear in virtual reality (VR): fear elements, coping reactions, immediate and next-day fright responses toward a survival horror zombie virtual reality game. Computers in Human Behavior, Vol. 71, 350-361. doi: 10.1016/j.chb.2017.02.057.

Lynch, T., \& Martins, N. (2015). Nothing to fear? An analysis of college students' fear experiences with video games. Journal of Broadcasting \& Electronic Media, Vol. 59 (2),298-317. doi: 10.1080/ 08838151.2015.1029128.

Morton, L. (2012). Trick or treat: a history of Halloween. London: Reaktion.

Ndalianis, A. (2012). The horror sensorium: media and the senses. Jefferson, NC: McFarland. Öhman, A., \& Mineka, S. (2001). Fears, phobias, and preparedness: toward an evolved module of fear and fear learning. Psychological Review, Vol. 108 (3), 483-522. doi: 10.1037// 0033- 295X.108.3.483. R Core Team. (2016). R: A language and environment for statistical computing. Vienna: R Foundation for Statistical Computing. Retrieved from https://www.R-project.org/

Robinson, T., Callahan, C., \& Evans, K. (2014). Why do we keep going back? A Q method analysis of our attraction to horror movies. Operant Subjectivity: The International Journal of Q Methodology, Vol. 37 (1-2), 41-57. doi: 10.15133/j.os.2014.004

Sapolsky, R. M. (2017). Behave: The biology of humans at our best and worst. Penguin.

Schjoedt, U., Sørensen, J., Nielbo, K. L., Xygalatas, D., Mitkidis, P., \& Bulbulia, J. (2013). Cognitive resource depletion in religious interactions. Religion, Brain \& Behavior, 3(1), 39-55.

Tellegen, A., \& Atkinson, G. (1974). Openness to absorbing and self-altering experiences ('absorption'), a trait related to hypnotic susceptibility. Journal of Abnormal Psychology, Vol. 83 (3), 268-277. doi:

$10.1037 / \mathrm{h} 0036681$

Thompson, J. H., Teasdale, B., Duncan, S., Boas, E. van E., Budelmann, F., Maguire, L., \& Dunbar, R. I. M. (2018). Individual differences in transportation into narrative drama. Review of General Psychology, Vol. 22 (2), 210-219. doi: 10.1037/gpr0000130.

Tudor, A. (1997). Why horror? The peculiar pleasures of a popular genre. Cultural Studies, Vol. 11 (3), 443-463. doi: 10.1080/095023897335691. 
Weibel, D., Wissmath, B., \& Mast, F. W. (2010). Immersion in mediated environments: the role of personality traits. Cyberpsychology, Behavior, and Social Networking, Vol. 13 (3), 251-256. doi: 10.1089=cyber.2009.0171

Wilson, B., Hoffner, C., \& Cantor, J. (1987). Children's perceptions of the effectiveness of techniques to reduce fear from mass media. Journal of Applied Developmental Psychology, Vol. 8 (1), 39-52. doi: 10.1016/0193-3973(87)90019-0.

Xygalatas, D., Mitkidis, P., Fischer, R., Reddish, P., Skewes, J., Geertz, A. W., Roepstorff, A. \& Bulbulia, J. (2013). Extreme rituals promote prosociality. Psychological science, 24(8), 1602-1605. Xygalatas, D., Schjoedt, U., Bulbulia, J., Konvalinka, I., Jegindø, E. M., Reddish, P., Geertz, A. W. \& Roepstoff, A. (2013). Autobiographical memory in a fire-walking ritual. Journal of Cognition and Culture, 13(1-2), 1-16.

Zillmann, D., \& J. B. Weaver, III. (1996). Gender-socialization theory of reactions to horror. In J. B. Weaver \& R. Tamborini (Eds.), Horror films: research on audience preference and reactions, (pp. 81101). Mahwah, NJ: Lawrence Erlbaum. 